\title{
Musical Criticism and Music Education
}

\author{
Keith Swanwick
}

\section{Introduction}

I am concerned here with the concept of musical analysis and its role in school and college education. My starting point is simply that musical analysis is the most important branch of musical criticism.

By criticism I mean any discourse about music involving judgement or appraisal at any level. The range of critical comment may be wide. There can be simple expressions of preference: "I like it", or, "I do not like it". There might be talk about the social or historical context of a musical work: "it is Baroque", "it is Heavy Metal", or, "it is a piece from the composer's middle period". Both of these types of statement can be part of musical criticism but they are not by themselves analytical. Critical statements that have analytical force must by definition say something about how a particular piece of music functions. All analysis is musical criticism but not all criticism is analysis. Analysis cannot be simply an expression of preference or a statement about the social or historical context of a piece of music. (I should make it clear that by "piece of music" I include improvisations and other non-notated forms of music). Critical statements that are simple expressions of preference or statements about context are not particularly helpful to the process of music education. For this reason I shall confine myself to the branch of criticism we call analysis.

Analysis is essentially discourse concerned with the internal functioning of a specific musical object. It is about the integrity of a particular work. To be more accurate, analysis is discourse about our perceptions of a musical object. From an educational perspective it is not helpful to conduct musical analysis as though a work existed independently of individual perceptions of it and in classrooms we have to conduct musical analysis in a way that involves students engaging with music in his or her own way. This is not to deny the autonomy of a musical object. There are limits to the range of statements that can be made about a musical work, bevond which one has to suspect either that the listener has not really been attending, or, that there is difficulty in conversing about the experience.

Musical analysis is not necessarily revealed in verbal or scholarly behaviour. It can take place at various levels; for example, in practical workshops where students are composing or improvising music. Here a teacher might ask questions to stimulate analysis. "What would the effect be if we played a cymbal here instead of a triangle?" "What makes that passage sound so brilliant? "Should this phrase be played so boldly or be more tentative?" "Does this passage hold our attention when played so slowly (or so quickly?)" These 
questions can be answered in practical ways, by musical experiment or demonstration, though verbal discourse is, of course, very important in any educational transaction.

I wish to assert that there are four fundamental dimensions of analytical discourse.

1) There can be discourse about the management of sonorities; about the soundscape of a work, impressions of timbre, texture, register, or loudness level.

2) There can be discourse about expressive character; the general atmosphere of a piece, its dramatic levels, or the specific gesture of a single phrase.

3) There can be discourse about structural relationships; the way expressive gestures relate to other gestures, how music undergoes continual metamorphosis and in so doing keeps us alert and attentive.

4) There can be discourse about the value of a work; not simply a personal prejudice for or against opera or rock music, but an awareness of the "meaningfulness" of a particular work for an individual listener in a certain time and place.

It seems impossible to find any analytical statement which does not fall into one of these four categories. If we are really attending to music, we are bound to assess the effect and control of sonorities, the management of the sound surface, the quality of the tonal experience itself; we are also conscious of the character of music, whether it is heavy, or light, flowing or angular; we many also look for coherence, ways in which musical gestures evolve, relate, contrast, or suggest or deny a sense of direction. We may also come to judge the place of a musical encounter in our own matriz of values, understanding its significance for us as a human being.

In the University of London, Institute of Education we have observed these modes of critical analysis emerging in the musical development of children. We chose to investigate analysis through practical music-making rather than through talk or writing, in the same way that it is possible to estimate linguistic grammatical understanding from the actual daily use of language rather than from a direct discussion of grammar. The theoretical rationale underlying this work was partly declared in the book, A Basis for Music Education (1979) and later developed in a public lecture, The Arts in Education: dreaming or wide awake?, delivered on 4 November, 1982 and subsequently published in 1983. In this paper I argued that the essential elements of any form of artistic engagement are mastery, imitation and imaginative play and that these psychological processes have corresponding artistic elements, namely the handling and perception of sensory materials, expressive character and structure, what I have called the first three modes of analysis.

The thesis is further developed in Music, Mind and Education, (Swanwick, 1988), where it is relate do the study of children's musical development. Between 1981 and 1985 we collected recordings of 745 compositions from 48 children aged between 3 and 15. One of our problems was: could these compositions be grouped into a coherent framework? As the data began to unfold it 
became possible to develop and refine the theoretical model. We found encouraging and sympathetic resonances in the literature, including work by Moog (1976), Gardner (1973), Ross (1984) and Bunting (1977).

We are able to locate the children's compositions into the four dimensions of musical analysis: materials, expression, form and value. By closer study we became more confident and each of these four levels came to be seen as embodying a polarity. Visual representation requires the illusion of three dimensions, that of a spiral, or perhaps more accurately, a helix. (Figure 1)

In general, children seem to move upwards as they become older and more musically experienced. On the left side are the aspects of music that have affective significance for the individual the exploration of the sensory qualities of sound; personal expressiveness; structural speculation; commitment to the symbolic significance of music. On the right side is the public domain: skilful mastery of sound materials; the conventions of the musical vernacular; idiomatic authenticity; the systematic extension of musical possibilities.

Only a very brief description is possible here and the ages shown relate only to our London sample.

\section{Materials}

Sensory: up to about the age of three, young children appeared to be primarily responsive to the direct impressiveness of sound phenomena, particularly timbre and dynamic levels. There is a much experimentation with and exploration of musical instruments and vocal soud.

Manipulative: children are acquiring techniques involved in handling instruments, organising regular pulse and using technical devices suggested by the physical structure and layout of available instruments. The manipulative mode was most apparent in the compositions of children around the age of four and five.

\section{Expression}

Personal expressiveness: strong personal expression was most evident in compositions around the ages of four to six years. This becomes particularly apparent through the exploitation of changes of speed and loudness levels. Musical ideas are essentially "programmatic" and the process of invention appeared to be very spontaneous.

The vernacular: children gravitated towards established expressive musical conventions: marches, lullabies and so on. Phrases tended to fall into standard two, four or eight bar units with regular metrical organisation. The vernacular mode began to appear at around the age of five but was more clearly established by seven or eight years. 


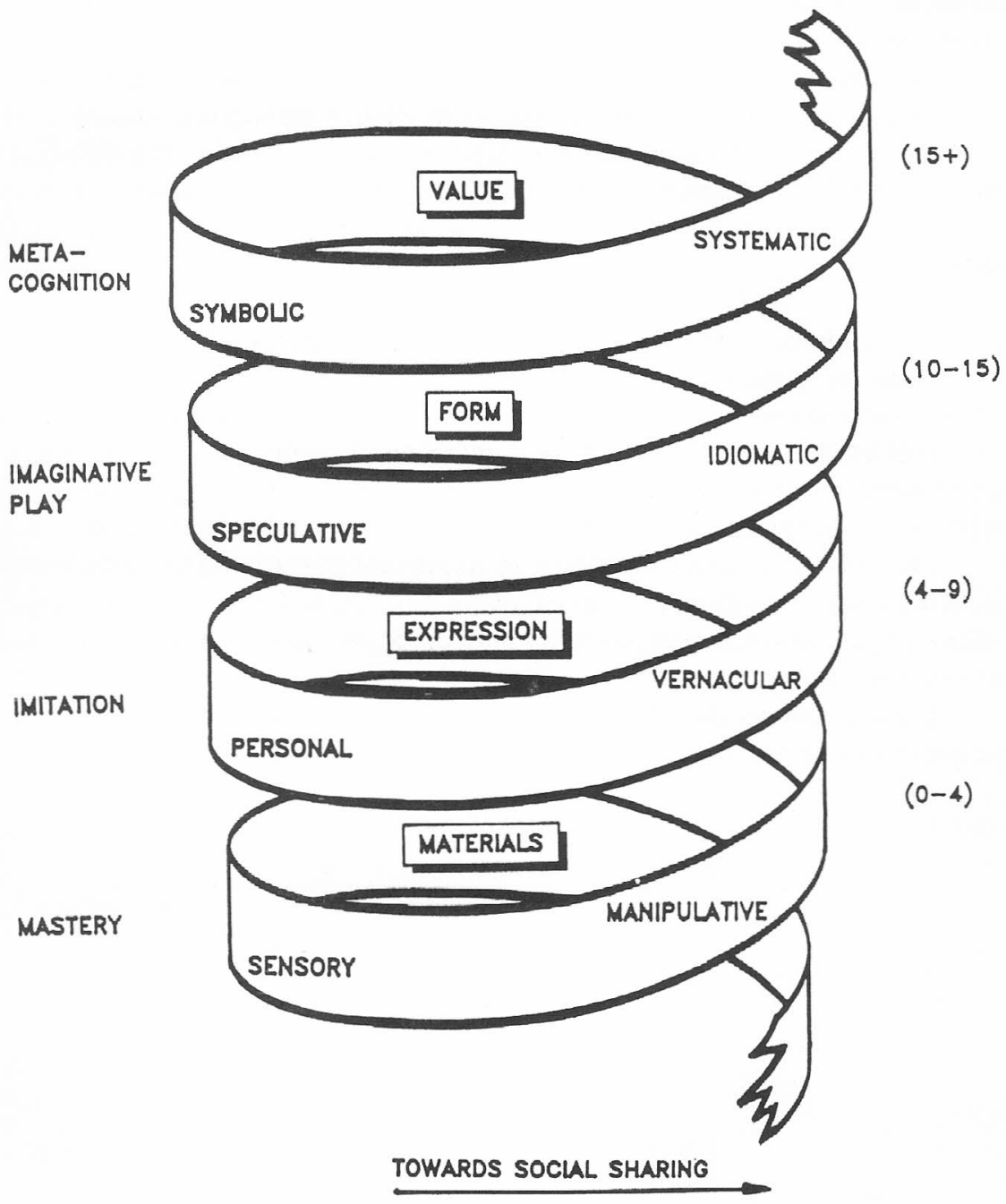

Swanwick and Tillman - 1985 


\section{Form}

The speculative: repetition of vernacular patterns is broken by imaginative deviations. Surprises occur as children deliberately explore structural possibilities, looking to contrast, overturn or very musical ideas. Speculative compositions were sometimes found earlier, but between the ages of nine and eleven was the most frequent time.

The idiomatic: around the ages of $13-14$, structural surprises became more firmly integrated into longer pieces in clearly identifiable idioms. Structural and expressive elements were located in emulated models and differentiated stylistic practices, often deriving from the popular musical styles.

\section{Value}

The symbolic: particular pieces of music, often certain shapes of phrase or a harmonic progression become highly significant for an individual. There is a growing consciousnesse of music's affective power and a tendency to reflect on this experience and to communicate something of commitment to others. The age of about 15 and beyond would seem to be optimum, though from this age point we did not at first have sufficient data for statistical confirmation.

The systematic: music becomes an important part of a value system and is conceptualised in ways which may be historical, musicological, psychological or philosophical. Musical compositions may be based on sets of newly generated musical materials.

Figure 2 shows the emergent modes of development at four agelevels on the patterns of analysis given in the spiral (Swanwick and Tillman, 1986).

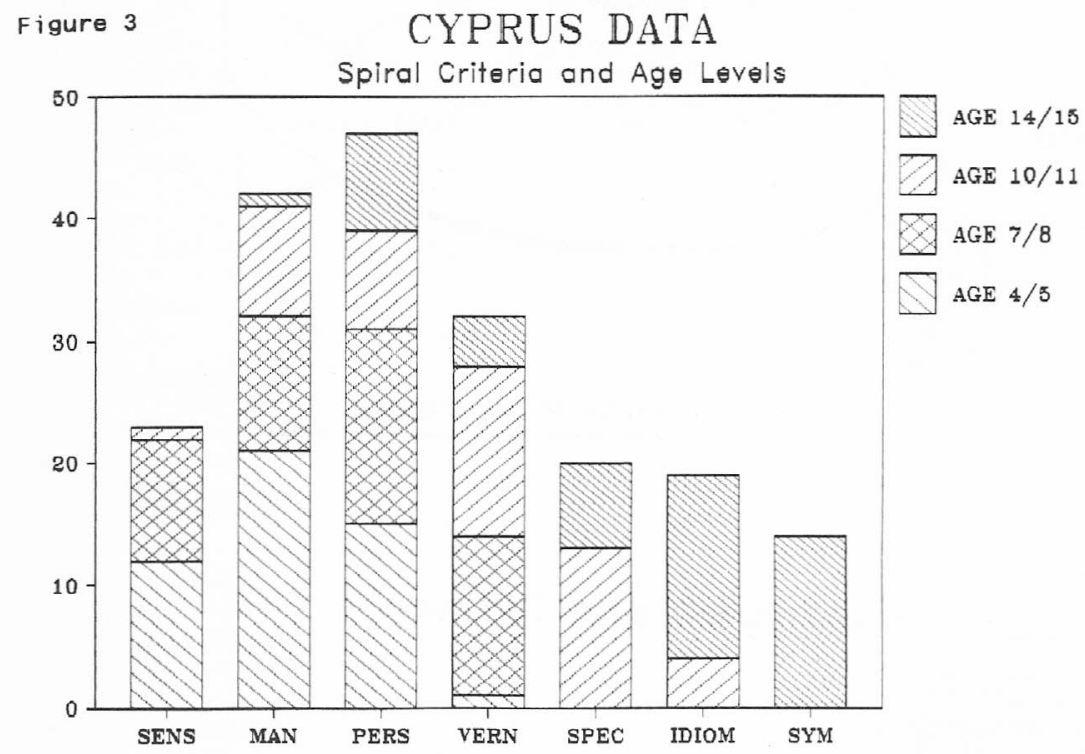


Replication of this work became essential and we were able to continue the investigation in a different cultural setting, the greek island of Cyprus. (This data became available thanks to Michael Stavrides, who is the Music Inspeccor for the island and currently a research student with the writer.

\section{The Cyprus Data}

During 1990 we collected recordings from several primary and secondary schools in Cyprus and assembled 28 items in random order on tape. We played this to seven teachers of music Britain who were asked to place each composition in a category description from the spiral (Swanwick, 1991).

Figure 3 shows that the spiral modes arrive in the predicted sequence. The Sensory, Manipulative and Personal Expressions levels are already in place by age $4 / 5$; by age $7 / 8$ the Vernacular is established; by $10 / 11$ the Speculative appears; and compositions at age 14/15 show the first emergence of the Symbolic mode.

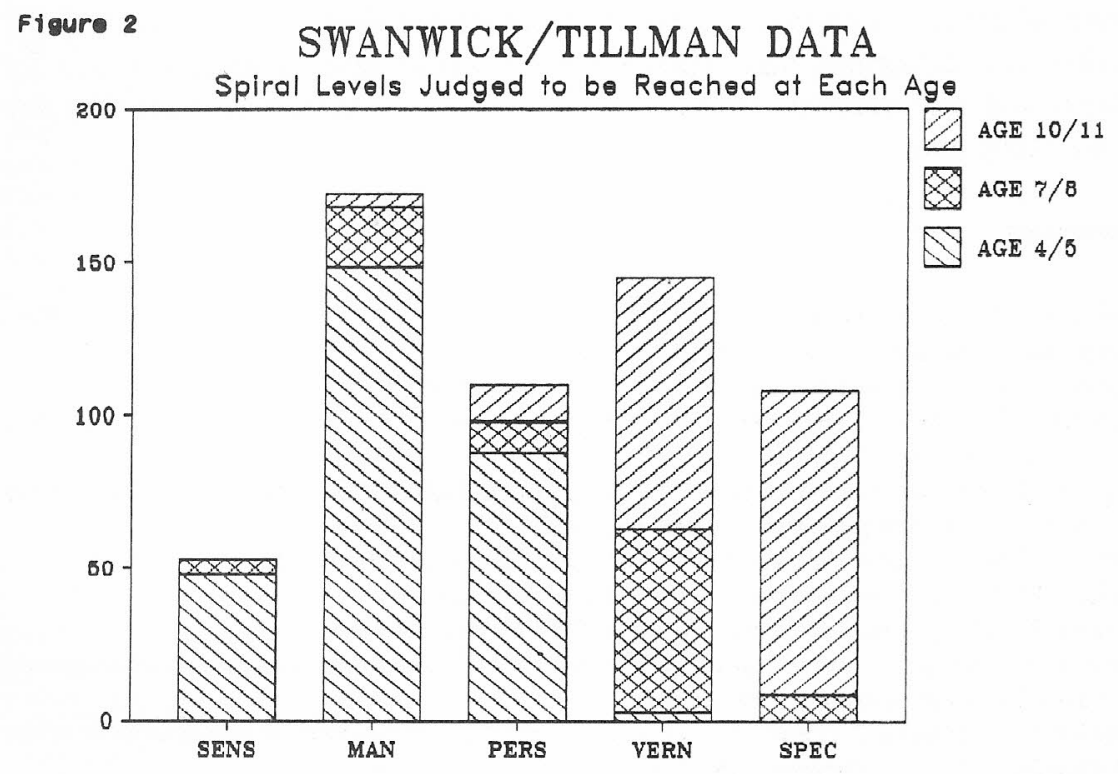

From this we also note that, although the sequential order of development may be identical, among the older age groups the compositions of the UK children appear generally to be less variable in level than those of their Cyprus peers.

\section{Conclusion}

Thus the pattern of musical development can be seen to follow an analytical hierarchy. The effective teacher is always trying to have students analyse 
music but needs to know on what level analytical discourse might be meaningful. That is what distinguishes formal education in schools and colleges from music encountered mored casually "on the street" or in the media.

The articulation of analytical judgements among children in school will often be in practical musical terms rather than words and we may be best able to assess their analytical capabilities by attending to the music they make rather than what they say about music. The skills of verbal discourse are rather different from the skills of musical discourse and it may be possible for someone inarticulate in words to be analytical and sensitive in a practical music context.

Indeed, verbal discourse cannot replace direct musical experience and may even interfere with musical encounter. Such was the situation in British schools some years ago, though not generally now, where at least $50 \%$ of time in music lessons is spent in practical music making. Even so, sensitive verbal discourse about musical encounters is an important part of the educational process.

It is my hope that this inquiry into the nature and dimensions of critical analysis is helping to enrich classroom transactions and assist the teacher to function as a discerning and articulate music critic, able to analyse music by students and with students in order to respond appropriately to what they say and how they play.

\section{References}

Bunting, R. (1977). The common language of music, music in the secondary school curriculum. Working Paper 6, Schools Council, York University.

Gardner, H. (1973). The arts and human development. New York: Wiley.

Hargreaves, D.J. (1986). Developmental psychology and music education. Psychology of Music, v. 14, n. 2 , p. 83-96.

Moog, H. (1976). The musical experience of the pre-school child. Translated by Claudia Clarke. London: Schott, First published in Germany, 1968.

Paynter, J. (1982). Music in the secondary school curriculum. Cambridge: CUP.

Ross, M. (1984). The aesthetic impulse. Oxford: Pergamon Press.

Swanwick, K. (1979). A basis for music education. Windsor: NFER-Nelson.

Swanwick, K. (1983). The arts in education: dreaming or wide awake? Special Professorial Lecture, London University Institute of Education.

Swanwick, K. \& Tillman, J. (1986). The sequence of musical development. British Journal of Music Education, v. 3, n. 3, November 1986, Cambridge University Press.

Swanwick, K. (1988). Music, mind and education. London: Routledge.

Swanwick, K. (1991). Further research on the musical development sequence. Journal of Psychology of Music, 19, p. 22-32.

Keith Swanwick, professor of music education - University of London, Institute of Education. 